\title{
Compressão Venosa Extrínseca Pós-Escleroterapia
}

Ivo CS. ${ }^{1}$

${ }^{1}$ Belo Horizonte - Brasil.

E-mail: claudiosivo@yahoo.com.br

Ivo, C.S. 2013. Compressão Venosa Extrínseca Pós-Escleroterapia, p.38. In: Bastos, Francisco Reis. Anais do V Simpósio Internacional de Flebologia [Blucher Medical Proceedings n.1 v.1]. São Paulo: Blucher, 2014

http://dx.doi.org/10.5151/medpro-flebo-SIF_19
O tratamento dos diversos tipos de varizes de membros inferiores é controverso. São empregadas operações, esclerose e a associação desses métodos.

A escleroterapia, principalmente a química, é empregada em todos os tipos de varicosidades com o objetivo de promover a fibrose do vaso e seu consequente desaparecimento.

Nesse processo, observa-se lesão endotelial com exposição do tecido subendotelial e aderência de plaquetas. Essas alterações desencadeiam a cascata de coagulação formando trombo na luz do vaso.

A presença de trombo é indesejável, pois a sua persistência aumenta a possibilidade de recanalização, pode determinar uma periflebite e, por último, resultar em hipercromia cutânea nos trajetos venosos, decorrente da deposição de hemossiderina na derme, secundária ao extravasamento de hemácias através da parede do vaso tratado, oriundas do trombo formado na luz do vaso em esclerose.

Visando prevenir a formação de trombo muito extenso no vaso em tratamento, vários autores preconizam compressão extrínseca pós-esclerose com o objetivo de esvaziá-lo da maior quantidade de sangue possível.

No pós-esclerose de telangiectasias, o uso de compressão é controverso, no entanto, no tratamento de varizes de veias reticulares e das de maior calibre, em especial tronculares, parece haver uma concordância no uso da compressão. Porém não há consenso sobre o tempo necessário para que essa compressão seja efetiva na prevenção ou diminuição dos coágulos dentro dos vasos e qual a melhor maneira de realizá-la.

São necessários, portanto, mais estudos para se chegar a uma conclusão do tempo mínimo de compressão necessário, após a injeção do esclerosante, para que não ocorra a formação de coágulo após a retirada do método compressivo empregado.

Palavras-chave: Escleroterapia, Varizes, Soluções Esclerosantes. 